\title{
KAHANDAAN NG MGA GURO NA NAGTUTURO NG ASIGNATURANG FILIPINO SA PAGGAMIT NG GOOGLE CLASSROOM
}

\author{
Rachel D. Buenviaje \\ Teacher II , Department of Education, , Masico National High School, Masico Pila, Laguna, Philippines
}

Article DOI: $\underline{\text { https://doi.org/10.36713/epra7754 }}$

DOI No: 10.36713/epra7754

\begin{abstract}
ABSTRAK
Ito ang lagom, ang mga natuklasan, ang konklusyon at rekomendasyon na kaugnay sa Kahandaan ng mga Gurong Nagtuturo ng Asignaturang Filipino sa Paggamit ng Google Classroom sa Laguna State Polytechnic University Taong Panuruan 2020-2021. Ang mga datos sa nasabing pananaliksik ay galling sa labing-isa (11) guro mula sa iba't ibang kolehiyo ng nasabing unibersidad upang bigyang kasagutan ang mga inilatag na katanungan ng mananaliksik. Deskriptibong disenyo ng pananaliksik ang ginamit sa pag-aaral at sa pamamagitan ng frequency at percentage upang malaman ang simpleng pagbilang sa bawat sagot sa mga tanong, sa pagkuha ng antas ng kahandaan ng mga guro na nagtuturo ng Asignaturang Filipino sa paggamit ng google classroom, paggamit ng Uri ng Dulog sa Panitikan at Wika ay gagamitin ang Mean at Standard Deviation at Multiple Regession para malaman ang epekto ng profayl ng mga guro, kahandaan ng mga Guro na Nagtuturo ng Asignaturang Filipino sa paggamit ng google classroom, paggamit ng uri ng Dulog sa Panitikan at Wika.

Ang Estado ng Profayl ng mga Guro Una, Edad, nakakuha ng bilang pito (7) ang nasa edad na 29 gulang pababa. Pangalawa ang Kasarian marami ang bilang ng mga gurong lalaki na may bilang na anim (6) sinundan ng mga gurong babae na may bilang na (5) Pangatlo, Kolehiyong kinabibilangan nakakuha ng pantay na bilang ang "College of Arts and Sciences" at "College of Teacher Education" na may bilang, Pang-apat, Taon ng Pagtuturo pinakamataas ang 1 hanggang 5 taon na bilang na 8.

Ang antas ng kahandaan ng mga guro na nagtuturo ng Asignaturang Filipino sa paggamit ng google classroom batay sa Personal na Kamalayan, Kawilihan, Aksesibiliti, Pagsasanay, Talakayan at Takdang-Aralin ay kapwa nakakuha ng ganap na sumasang-ayon at literal na paliwanag na lubhang mataas.

Ang antas ng Paggamit ng uri ng Dulog sa Panitikan batay sa Pamamaraang Tanong-Sagot, Pamamaraang Paulat, at Pagkatutong Interaktibo ay kapwa nakakuha ng ganap na sumasang-ayon at literal na paliwanag na lubhang mataas.

Ang antas ng Paggamit ng Uri ng Dulog sa Wika batay sa Pamamaraang Pabuod at Pamamaraang Panayam ay kapwa nakakuha ng ganap na sumasang-ayon at literal na paliwanag na lubhang mataas.

May makabuluhang epekto ng Profayl ng mga guro sa paggamit ng Uri ng Dulog sa Panitikan at sa Wika.

May makabuluhang epekto ng kahandaan ng mga guro na nagtuturo ng asignaturang Filipino sa Paggamit ng google classroom batay sa Paggamit ng Dulog sa Panitikan at Wika.

Ang resulta sa nasabing pananaliksik ay sumasalamin an lubhang katanggap-tanggap ang paggamit ng aplikasyong Google Classroom sa pagtuturo sa Asignaturang Filipino ng mga Guro mula sa unibersidad ng Laguna State Polytechnic University.

Inererekomenda ng mananaliksik na ang mga guro ay patuloy na dumalo sa mga palihan tungkol sa paggamit ng google classroom upang pag-ibayuhin pang ganap ang pagkatuto nila nito.
\end{abstract}




\section{EPRA International Journal of Research and Development (IJRD)}

\section{PANIMULA}

Nararapat na magkaroon ng mga makabagong paraan o istratehiya ang mga guro gamit ang mga aplikasyon mula sa google upang patuloy namaibahagi ang mga aralin sa mga mag-aaral at patuloy na magkaroon ng panibagong kaalaman gamit ang teknolohiya na magiging gabay sa pag-aaral at pagkatuto ng mga mag-aaral. Ang Google Classroom ay isang suite ng pag-aaral para sa paaralan na maaaring idagdag sa Google Apps para sa mga pangedukasyon na ginagamit na magiging gabay sa pagtuturo at pagkatuto ng mga mag-aaral sa mga aralin.

Ayon kay Santiago (2011), ang gamit ng elearning ay mabuting paraan ng paglilipat ng kaalaman mula sa guro patungo sa mga mag-aaral.

Ito ay isang pananaw na maaaring maisakatuparan sa pamamamgitan ng paglalapat at paggamit ng mga guro sa/ng teknolohiya sa paraan ng pagtuturo sa iba'tibang asignatura tulad ng Filipino. Nagiging mabisa ang isang pamamaraan kung ito ay patuloy napag-aaralan at gagamitin bilang daluyan ng pag-aaral ng mga mag-aaral naginamit bilangi nstrumento ng pagtuturo ng mga guro sa kasalukuyang panahon upang mapunan ang pangangailangan ng mga mag-aaral pagdating sa kanilang edukasyon at sa paghubog ng kanilang kaalaman, talento at kakayahan.

\section{LAYUNIN}

Ang pangunahing layunin ng pag-aaral na ito ay matukoy ang kabisaan ng paggamit ng Google Classroom sa pagtuturo ng asignaturang Filipino ng mga guro sa ng Kolehiyo ng Panggurong Edukasyon at Kolehiyo ng Sining at Agham ng Laguna State Polytechnic University, Sta Cruz, Campus

Upang makamtan ang nabanggit na layunin, pinagsikapan ng mananaliksik na tukuyin ang mga sumusunod; batay sa:

1. Ano ang Estado ng Profayl ng mga Guro

\author{
1.1 Edad; \\ 1.2 Kasarian; \\ 1.3 Kolehiyong Kinabibilangan; at \\ 1.4 Taon ng Pagtuturo?
}

2. Ano ang antas ng kahandaan ng mga guro na nagtuturo ng Asignaturang Filipino sa paggamit ng google classroom batay sa:

2.1 Personal na Kamalayan;

2.2 Kawilihan;

2.3 Aksesibiliti;
2.4 Pagsasanay;

2.5 Talakayan; at

2.6 Takdang-Aralin?

3. Ano ang antas ng Paggamit ng uri ng Dulog sa Panitikan batay sa:

3.1 Pamamaraang Tanong-Sagot;

3.2 Pamamaraang Paulat; at

3.3 Pagkatutong Interaktibo;

4. Ano ang antas ng Paggamit ng Uri ng Dulog sa Wika batay sa:

4.1 Pamamaraang Pabuod; at

4.2 Pamamaraang Panayam?

5. May makabuluhang bang epekto ang Profayl ng mga guro sa paggamit ng Uri ng Dulog sa Panitikan?

6. May makabuluhang bang epekto ang Profayl ng mga guro sa paggamit ng Uri ng Dulog sa Wika?

7. May makabuluhan bang epekto ang kahandaan ng mga guro na nagtuturo ng asignaturang Filipino sa Paggamit ng google classroom batay sa Paggamit ng Dulog sa Panitikan.

8. May makabuluhan bang epekto ang paggamit ng google classroom sa kahandaan ng mga guro na nagtuturo ng asignaturang Filipino batay sa Paggamit ng Dulog sa Wika.

\section{METODOLOHIYA NG PANANALIKSIK}

Ang kabanatang ito ay kinapapalooban ng pananaliksik ng pag-aaral, sampling at populasyon, instrumentong ginamit, paraan ng pagkalap ng datos at istatistikal na pamamaraan.

\section{Tagatugon sa Pananaliksik}

Sa pag-aaral ang mga tagatugon ay mga guro mula sa iba't ibang Kolehiyo ng Laguna State Polytechnic University, Sta. Cruz Laguna Ang mga guro ay may kabuuang bilang na labing-isa (11) may lima ( 5 ) lalaki at anim ( 6) babae mula sa mga kolehiyo na nagtuturo ng Asignaturang Filipino.

Sa pagsasagawa ng pananaliksik na ito, ang mananaliksik ay gumamit ng "Purposive Sampling Technique".Isang uri ng nonprobability o nonrandom sampling na ibinabatay ang pagpili ng sampol sa layunin ng pag-aaral at sa pasya ng mananaliksik kung ano ang kinakailangang malamang impormasyon (Etikan et. al 2016)

\section{Paraan ng Pananaliksik}

Upang magtagumpay ang isang pananaliksik ay kinakailangang magbasa, mangalap $\mathrm{ng}$ datos at 
maghanda ng mga kagamitang kapakipakinabang sa anumang pag-aaral ang mga mananaliksik.

Ang instrumentong ginamit sa pagkalap ng mga datos ay mga talatanungan o (questionaire) kinapapalooban ito ng mga katanungan na kinakailangang sagutin ng labing-isang (11) guro mula sa iba't ibang kolehiyo. Ang talatanungan na nilikha ng mananaliksik ay magbibigay kasagutan sa kahandaan ng mga guro sa paggamit ng google classroom sa pagtuturo ng asignaturang Filipino ang mga katanungan ay nahati sa tatlong kategorya, ang unang bahagi ay may kaugnayan sa estado ng mga guro batay sa edad, kasarian, kolehiyong kinabibilangan, at taon ng pagtuturo, ang pangalawang bahagi ay tungkol sa paggamit ng uri ng dulog sa Panitikan na kinabibilangan ng mga katanungan tungkol sa paggamit ng Pamamaraang Tanong-Sagot, Pamamaraang Paulat at Pagkatutong Interaktibo at sa huling bahagi ng katanungan ay ang paggamit ng uri ng dulog sa wika na may mga katanungan tungkol sa Pamamaraang Pabuod at Pamamaraang Panayam.

Sa bahagi naman ng pakikipagpanayam at pagbibigay ng talatanungan:una,ang mananaliksik ay gagawa ng talatanungan na ipapavalideyt upang maging maayos ang daloy ng distribusyon sa pamamagitan ng paglikha ng katanungan mula sa google form at matapos ang paglikha ng mga talatanungan ay iisa-isahin ang mga tagatugon upang mabigyan ng imbitasyon sa pamamagitan ng pagpapasa ng link at ito ang magsisilbing gabay sa magiging pagsasagot ng mga tagatugon.; ikalawa, pagdulog sa dekano at dekano ng kolehiyong kinabibilangan ng mga guro ng kolehiyo at paghingi ng pahintulot upang mabigyan ang mga tagatugon na nagtuturo ng asignaturang Filipino; ikatlo, pagbibigay ng link sa mga piling guro upang masagutan ang talatanungan mula sa google form na nilikha ng mananaliksik,matapos masagutan ang mga lkatanungan ay makikita na ang mga kasagutan ng mga tagatugon; ikaapat, ang mga datos na natipon o nakalap ay aayusin sa talahanayan, aanalisahin at bibigyan ng interpretasyon ng mananaliksik; at panghuli, ilalagay ang mga mahahalagang impormasyong nalikom sa isang maayos na pagkakahanay sa nararapat nitong lugar sa tesis.

\section{Istatistikal na Pamamaraan}

Ginamit ng mananaliksik ang Frequency at Percentage upang makita ang profayl ng mga guro na nagsagot ng talatanungan. Ang frequency ay ang simpleng pagbilang sa mga sagot sa bawat tanong.

Para sa pagkuha ng antas ng kahandaan ng mga guro na nagtuturo ng Asignaturang Filipino sa paggamit ng google classroom, paggamit ng uri ng dulog sa Panitikan at Wika ay gagamitin angg Mean at Standard Deviation.

Para malaman ang epekto ng profayl ng mga guro, kahandaan ng mga guro na nagtuturo ng asignaturang Filipino sa paggamit ng google Classroom ,paggamit ng uri ng dulog sa Panitikan at Wika ang gagamiting istatistikal na pamamaraan ay Regression Analysis . Gumamit ang mananaliksik ng adjusted Rsquare at F-value.

\section{KINALABASAN, MUNGKAHI AT KONKLUSYON}

Kinalabasan

Ang pangunahing layunin ng pag-aaral na ito ay matukoy ang kabisaan ng paggamit ng Google Classroom sa pagtuturo ng asignaturang Filipino ng mga guro sa ng Kolehiyo ng Panggurong Edukasyon at Kolehiyo ng Sining at Agham ng Laguna State Polytechnic University, Sta Cruz, Campus taongpanuruan 2020-2021.

Batay sa antas ng kahandaan ng mga guro na nagtuturo ng Asignaturang Filipino sa paggamit ng google classroom batay sa Personal na Kamalayan, Kawilihan, Aksesibiliti, Pagsasanay, Talakayan at Takdang-Aralin ay may puna na ganap na sumasangayon at literal na paliwanag na lubhang mataas.

Batay sa Antas ng paggamit ng uro ng Dulog sa Panitikan at Wika ay may puna na ganap na sumasang-ayon at literal na paliwanag na lubhang mataas.

Lumabas sa resulta na ang mga guro na nagtuturo ng asignaturang Filipino ay may kahandaan sa paggamit ng google classroom ay katanggap-tanggap at mabisa

bilang kagamitang pampagtuturo.

Ang Profayl ng mga guro ay nakakaimpluwensya sa kahandaan ng mga guro na nagtuturo ng asignaturang Filipino sa paggamit ng google classroom.

Mabigyang puna ang epektibong implikasyon ng paggamit ng Google Classroom sa pagtuturo ng mga guro at pagkatuto ng mga mag-aaral sa Asignaturang Filipino gamit ang teknolohiya at ang aplikasyon 


\section{EPRA International Journal of Research and Development (IJRD)}

Volume: 6 | Issue: 7 | July 2021

- Peer Reviewed Journal

MGA TALAHANAYAN

Talahanayan 1. Antas ng kahandaan ng mga guro na nagtuturo ng Asignaturang Filipino sa paggamit ng google classroom batay sa Personal na Kamalayan

\begin{tabular}{|c|c|c|c|}
\hline Mga Pahayag & Mean & SD & Puna \\
\hline $\begin{array}{l}\text { Nakagagamit ng Stream sa pag-aanunsyo, } \\
\text { paparating na proyekto o mga petsa ng pagsubok o } \\
\text { mga paalala tungkol sa gagawing aktibidad. }\end{array}$ & 4.82 & 0.40 & Ganap na Sumasang-ayon \\
\hline $\begin{array}{l}\text { May sapat ng kakayahan sa paglikha ng mga gawain } \\
\text { patungo sa mga mag-aaral gamit ang google } \\
\text { classroom. }\end{array}$ & 4.82 & 0.40 & Ganap na Sumasang-ayon \\
\hline $\begin{array}{l}\text { Nakakapag-eksplor gamit ang Google Classroom sa } \\
\text { oras ng talakayan at pagkatapos nito. }\end{array}$ & 4.73 & 0.47 & Ganap na Sumasang-ayon \\
\hline $\begin{array}{l}\text { Naitatakda sa oras ang mga kinakailangang dulog sa } \\
\text { pagbubukas at pagtalakay ng mga aralin }\end{array}$ & 4.73 & 0.47 & Ganap na Sumasang-ayon \\
\hline $\begin{array}{l}\text { Nagagamit ang Google Classroom nang walang } \\
\text { hirap at kayang sumunod sa mga panuntunan sa } \\
\text { paggamit ng aplikasyon. }\end{array}$ & 4.73 & 0.47 & Ganap na Sumasang-ayon \\
\hline $\begin{array}{l}\text { Nakalilikha ng sariling link para sa pag-iimbita ng } \\
\text { mga grupo ng mga mag-aaral batay sa kanilang } \\
\text { kinabibilangan at ang pagbibigay ng code. }\end{array}$ & 4.91 & 0.30 & Ganap na Sumasang-ayon \\
\hline $\begin{array}{l}\text { Nabibigyang pansin ang mga araling inilalatag sa } \\
\text { google classroom at mga site na hindi maaaring } \\
\text { paghanguan ng mga aralin. }\end{array}$ & 4.82 & 0.40 & Ganap na Sumasang-ayon \\
\hline $\begin{array}{l}\text { Naibabahagi ng guro ang imbitasyon ng patungo sa } \\
\text { mag-aaral. }\end{array}$ & 4.91 & 0.30 & Ganap na Sumasang-ayon \\
\hline $\begin{array}{l}\text { Mas mabilis na natutukoy ang mga grado ng mga } \\
\text { mag-aaral mula sa mga isinumiteng gawain mula sa } \\
\text { araling tinalakay. }\end{array}$ & 4.82 & 0.40 & Ganap na Sumasang-ayon \\
\hline $\begin{array}{l}\text { Nasusuri ang grado ng mga mag-aaral sa kanilang } \\
\text { mga takdang-aralin mula sa nakalista sa google } \\
\text { classroom. }\end{array}$ & 4.91 & 0.30 & Ganap na Sumasang-ayon \\
\hline \multicolumn{4}{|l|}{$\begin{array}{l}\text { Overall Mean: } 4.82 \\
\text { Standard Deviation: } 0.387 \\
\text { Literal na paliwanag: } \text { Lubhang Mataas }\end{array}$} \\
\hline
\end{tabular}

Talahanayan 2. Antas ng kahandaan ng mga guro na nagtuturo ng Asignaturang Filipino sa paggamit ng google classroom batay sa Kawilihan

\begin{tabular}{|l|l|l|c|}
\hline Mga Pahayag & Mean & SD & Puna \\
\hline Masayang nagtuturo gamit ang google classroom. & 4.64 & 0.50 & $\begin{array}{c}\text { Ganap na } \\
\text { Sumasang-ayon }\end{array}$ \\
\hline Na-eenganyo na makilahok sa talakayan kasama ang mga mag-aaral. & 4.64 & 0.50 & $\begin{array}{c}\text { Ganap na } \\
\text { Sumasang-ayon }\end{array}$ \\
\hline $\begin{array}{l}\text { Napupukaw ang interes mula sa mga estratehiyang ginagamit sa pagtalakay sa } \\
\text { aralin. }\end{array}$ & 4.64 & 0.50 & $\begin{array}{c}\text { Ganap na } \\
\text { Sumasang-ayon }\end{array}$ \\
\hline $\begin{array}{l}\text { Lumalabas ang pagiging malikhain sa paglikha ng mga aralin gamit ang } \\
\text { aplikasyon }\end{array}$ & 4.73 & 0.47 & $\begin{array}{c}\text { Ganap na } \\
\text { Sumasang-ayon }\end{array}$ \\
\hline Nagiging aktibo sa oras ng talakayan gamit ang iba't ibang gawain mula sa aralin. & 4.82 & 0.40 & $\begin{array}{c}\text { Ganap na } \\
\text { Sumasang-ayon }\end{array}$ \\
\hline Mabilis na nakalilikha ng mga aralin gamit ang google classroom. & 4.91 & 0.30 & $\begin{array}{c}\text { Ganap na } \\
\text { Sumasang-ayon }\end{array}$ \\
\hline
\end{tabular}




\section{EPRA International Journal of Research and Development (IJRD)}

\begin{tabular}{|l|l|l|c|}
\hline $\begin{array}{l}\text { Nagkakaroon ng masayang ugnayan ang guro at mag-aaral gamit ang aplikasyon } \\
\text { na google classroom. }\end{array}$ & 4.55 & 0.52 & $\begin{array}{c}\text { Ganap na } \\
\text { Sumasang-ayon }\end{array}$ \\
\hline $\begin{array}{l}\text { Nagiging bukas sa mga pagbabagong nagaganap mula sa paggamit ng aplikasyon } \\
\text { mula sa mga panibagong nilalaman. }\end{array}$ & 4.82 & 0.40 & $\begin{array}{c}\text { Ganap na } \\
\text { Sumasang-ayon }\end{array}$ \\
\hline $\begin{array}{l}\text { Nagkakaroon ng maraming panahon upang makapaghanda na para sa panibagong } \\
\text { aralin. }\end{array}$ & 4.73 & 0.47 & $\begin{array}{c}\text { Ganap na } \\
\text { Sumasang-ayon }\end{array}$ \\
\hline $\begin{array}{l}\text { Nagkakaroon ng malalim at magandang samahan ang guro at mag-aaral sa bukas } \\
\text { na komunikasyon gamit ang aplikasyon. }\end{array}$ & 4.45 & 0.69 & $\begin{array}{c}\text { Ganap na } \\
\text { Sumasang-ayon }\end{array}$ \\
\hline $\begin{array}{l}\text { Overall Mean: 4.69 } \\
\text { Standard Deviation: } 0.484 \\
\text { Literal na paliwanag: Lubhang Mataas }\end{array}$ & & \\
\hline
\end{tabular}

Talahanayan 3. Antas ng kahandaan ng mga guro na nagtuturo ng Asignaturang Filipino sa paggamit ng google classroom batay sa Aksesibiliti

\begin{tabular}{|l|l|l|l|c|}
\hline Mga Pahayag & Mean & SD & Puna \\
\hline $\begin{array}{l}\text { Mabilis na makapasok sa link na nilikha sa google } \\
\text { classroom. }\end{array}$ & 4.82 & 0.40 & Ganap na Sumasang-ayon \\
\hline $\begin{array}{l}\text { Nagagamit ang cellphone sa pagbubukas ng aplikasyon na } \\
\text { google classroom. }\end{array}$ & 4.73 & 0.47 & Ganap na Sumasang-ayon \\
\hline $\begin{array}{l}\text { Nabubuksan ang google classroom gamit lamang ang } \\
\text { cellphone data. }\end{array}$ & 4.45 & 1.04 & Sanap na Sumasang-ayon \\
\hline $\begin{array}{l}\text { Hindi nagkakaroon ng interapsyon sa paggamit ng google } \\
\text { classroom sa pagpapasa ng mga gawain sa araling tinalakay. }\end{array}$ & 4.00 & 1.10 & Ganap na Sumasang-ayon \\
\hline $\begin{array}{l}\text { Nagagamit ang cellphone sa pagpapasa ng link patungo sa } \\
\text { mga grupo ng mga mag-aaral. }\end{array}$ & 4.55 & 0.82 & Ganap na Sumasang-ayon \\
\hline $\begin{array}{l}\text { Nakikita agad ng mga mag-aaral ang code nang pag-iimbita } \\
\text { sa pagpasok sa link na nagawa ng guro para sa kanilang } \\
\text { aralin. }\end{array}$ & 4.73 & 0.47 & Ganap na Sumasang-ayon \\
\hline $\begin{array}{l}\text { Nabubuksan ang google classroom kahit saan man } \\
\text { magpunta. }\end{array}$ & 4.36 & 1.03 & Ganap na Sumasang-ayon \\
\hline $\begin{array}{l}\text { Hind na kinakailangan pang lumabas ng bahay para } \\
\text { makasali sa klase. }\end{array}$ & 4.45 & 1.04 & Ganap na Sumasang-ayon \\
\hline $\begin{array}{l}\text { Maaaring dalawang device ang gamitin para sumali sa } \\
\text { nilikhang link ng guro. }\end{array}$ & 4.45 & 0.93 & Sumasang-ayon \\
\hline $\begin{array}{l}\text { Nabubuksan ang google classroom kahit cellphone hotspot } \\
\text { lang ang gagamitin para kumonekta. }\end{array}$ & 4.18 & 0.98 & \\
\hline $\begin{array}{l}\text { Overall Mean: 4.47 } \\
\text { Standard Deviation: 0.864 } \\
\text { Literal na paliwanag: Lubhang Mataas }\end{array}$ & & & \\
\hline
\end{tabular}

Talahanayan 4. Antas ng kahandaan ng mga guro na nagtuturo ng Asignaturang Filipino sa paggamit ng google classroom batay sa Pagsasanay

\begin{tabular}{|l|l|l|c|}
\hline Mga Pahayag & Mean & \multicolumn{1}{|c|}{ SD } & Puna \\
\hline $\begin{array}{l}\text { Isang kagamitan upang matasa at matukoy ang kakayan ng } \\
\text { mga mag-aaral. }\end{array}$ & 4.82 & 0.40 & Ganap na Sumasang-ayon \\
\hline $\begin{array}{l}\text { Nasusukat ang lebel ng kakayahan ng mga mag-aaral mula } \\
\text { sa mga gawaing inilalatag ng guro. }\end{array}$ & 4.64 & 0.50 & Ganap na Sumasang-ayon \\
\hline $\begin{array}{l}\text { Repleksyon ng pagkatuto ng mga mag-aaral mula sa tiyak } \\
\text { na aralin. }\end{array}$ & 4.55 & 0.69 & Ganap na Sumasang-ayon \\
\hline $\begin{array}{l}\text { Nasusubaybayan ang paglago ng mga mag-aaral mula sa } \\
\text { mga aralin. }\end{array}$ & 4.64 & 0.50 & Ganap na Sumasang-ayon \\
\hline
\end{tabular}




\section{EPRA International Journal of Research and Development (IJRD)}

\begin{tabular}{|l|l|l|l|}
\hline $\begin{array}{l}\text { Nasusubok ang kakayahan ng mga mag-aaral mula sa } \\
\text { kanilang nalikom na karunungan batay sa naibahagi ng } \\
\text { guro. }\end{array}$ & 4.64 & 0.50 & Ganap na Sumasang-ayon \\
\hline $\begin{array}{l}\text { Ginagamit upang makita ang ganap na pagkatuto ng mga } \\
\text { mag-aaral mula sa araling tinalakay. }\end{array}$ & 4.64 & 0.50 & Ganap na Sumasang-ayon \\
\hline $\begin{array}{l}\text { Naiisa-isa ang mga araling kinakailangan pang mabigyang } \\
\text { pansin sa mga mag-aaral }\end{array}$ & 4.64 & 0.50 & Ganap na Sumasang-ayon \\
\hline $\begin{array}{l}\text { Nalalaman ang araling higit na nauunawaan ng mga mag- } \\
\text { aaral. }\end{array}$ & 4.64 & 0.67 & Ganap na Sumasang-ayon \\
\hline $\begin{array}{l}\text { Nagiging ebidensya ng paglago at pagkatuto sa } \\
\text { asignaturang Filipino }\end{array}$ & 4.73 & 0.47 & Ganap na Sumasang-ayon \\
\hline $\begin{array}{l}\text { Nagiging gabay sa guro sa pagkuha ng resulta nang } \\
\text { kalakasan at kahinan ng mga mag-aaral. }\end{array}$ & 4.73 & 0.47 & Ganasang-ayon \\
\hline $\begin{array}{l}\text { Overall Mean: 4.66 0.512 } \\
\text { Standard Deviation: 0.512 } \\
\text { Literal na paliwanag: Lubhang Mataas }\end{array}$ & & \\
\hline
\end{tabular}

Talahanayan 5. Antas ng kahandaan ng mga guro na nagtuturo ng Asignaturang Filipino sa paggamit ng google classroom batay sa Talakayan

\begin{tabular}{|l|l|l|l|}
\hline Mga Pahayag & Mean & SD & Puna \\
\hline $\begin{array}{l}\text { Lunsaran sa pagkuha ng atensyon at interes ng mga mag- } \\
\text { aaral. }\end{array}$ & 4.55 & 0.52 & Ganap na Sumasang-ayon \\
\hline $\begin{array}{l}\text { Natutukoy ang hilig ng mga mag-aaral batay sa talakayan } \\
\text { ng guro at mag-aaral. }\end{array}$ & 4.55 & 0.69 & Ganap na Sumasang-ayon \\
\hline $\begin{array}{l}\text { Nabibigyang pansin ang kakayahang mental at pisikal } \\
\text { batay sa mga aktibidad na nilikha tungkol sa pagtalakay } \\
\text { sa aralin. }\end{array}$ & 4.55 & 0.69 & Ganap na Sumasang-ayon \\
\hline $\begin{array}{l}\text { Napapanatili ang pagiging buhay at masiglang talakayan } \\
\text { sa paggamit ng google classroom. }\end{array}$ & 4.55 & 0.69 & Ganap na Sumasang-ayon \\
\hline $\begin{array}{l}\text { Ang mga gawain ay sumasalamin sa hilig ng mga mag- } \\
\text { aaral sa at natatanggal ang kanilang pagkabagot. }\end{array}$ & 4.45 & 0.52 & Ganap na Sumasang-ayon \\
\hline $\begin{array}{l}\text { Pagkuha ng kasanayan ng mga mag-aaral na nabibigyan } \\
\text { pansin sa oras ng talakayan. }\end{array}$ & 4.36 & 0.50 & Ganap na Sumasang-ayon \\
\hline $\begin{array}{l}\text { Nakikita ang pagkakaisa ng mga mag-aaral sa } \\
\text { pagsasagawa nila ng aktibidad sa loob ng talakayan. }\end{array}$ & 4.45 & 0.52 & Ganap na Sumasang-ayon \\
\hline $\begin{array}{l}\text { Mas nagiging interisadong ang mga mag-aaral sa } \\
\text { asignaturang Filipino batay sa mga gawaing nilalahukan. }\end{array}$ & 4.64 & 0.50 & Ganap na Sumasang-ayon \\
\hline $\begin{array}{l}\text { Sumasalamin sa kawilihan at hilig ng mga mag-aaral } \\
\text { gamit ang mga leksyon sa pagtalakay sa google } \\
\text { classroom. }\end{array}$ & 4.45 & 0.52 & Ganap na Sumasang-ayon \\
\hline $\begin{array}{l}\text { Masayang natututo ang mga mag-aaral sa oras ng } \\
\text { talakayan. }\end{array}$ & 4.64 & 0.50 & \\
\hline $\begin{array}{l}\text { Overall Mean: 4.52 } \\
\text { Standard Deviation: 0.554 } \\
\text { Literal na paliwanag: Lubhang Mataas }\end{array}$ & & \\
\hline
\end{tabular}




\section{EPRA International Journal of Research and Development (IJRD)}

Talahanayan 6. Antas ng kahandaan ng mga guro na nagtuturo ng Asignaturang Filipino sa paggamit ng google classroom batay sa Takdang Aralin

\begin{tabular}{|l|l|l|l|}
\hline Mga Pahayag & Mean & SD & Puna \\
\hline $\begin{array}{l}\text { Nakikita na nahuhubog ang pagiging responsible ng mga mag- } \\
\text { aaral sa pagganap sa kanilang gawain. }\end{array}$ & 4.73 & 0.47 & Ganap na Sumasang-ayon \\
\hline $\begin{array}{l}\text { Natututunan ang wastong paglikha ng grado gamit ang google } \\
\text { classroom. }\end{array}$ & 4.82 & 0.40 & Ganap na Sumasang-ayon \\
\hline $\begin{array}{l}\text { Nabibigyan ng paunang kaalaman tungkol sa aralin na } \\
\text { binibigyan ng pansin. }\end{array}$ & 4.73 & 0.47 & Ganap na Sumasang-ayon \\
\hline $\begin{array}{l}\text { Natututunan ang paglikha ng mga gawain gamit ang google } \\
\text { classroom. }\end{array}$ & 4.73 & 0.47 & Ganap na Sumasang-ayon \\
\hline $\begin{array}{l}\text { Nasusubay-bayan ang pagkakaroon ng magandang ugnayan } \\
\text { ang mga mag-aaral sa kapwa mag-aaral sa pangangalap ng } \\
\text { impormasyon. }\end{array}$ & 4.73 & 0.47 & Ganap na Sumasang-ayon \\
\hline $\begin{array}{l}\text { Nabibigyang pansin ang mga kagamitang maaaring pangkunan } \\
\text { ng impormasyon tungkol sa takdang-aralin. }\end{array}$ & 4.73 & 0.47 & Ganap na Sumasang-ayon \\
\hline $\begin{array}{l}\text { Nagkakaroon ng palitan ng kaalaman mula sa mga nakalap na } \\
\text { impormasyon sa pagitan ng guro at mag-aaral. }\end{array}$ & 4.73 & 0.47 & Ganap na Sumasang-ayon \\
\hline $\begin{array}{l}\text { Nagiging bukas ang kaisipan sa mga impormasyong nakolekta } \\
\text { mula sa iba't ibang libro. }\end{array}$ & 4.73 & 0.47 & Ganap na Sumasang-ayon \\
\hline Nagiging bukas sa pagkuha ng impormasyon mula sa internet. & 4.73 & 0.47 & Ganap na Sumasang-ayon \\
\hline $\begin{array}{l}\text { Nagkakaroon ng mas malalim na pagkaunawa tungkol sa } \\
\text { aralin. }\end{array}$ & 4.82 & 0.40 & Ganap na Sumasang-ayon \\
\hline $\begin{array}{l}\text { Overall Mean: 4.75 } \\
\text { Standard Deviation: 0.438 } \\
\text { Literal na paliwanag: Lubhang Mataas }\end{array}$ & & & \\
\hline
\end{tabular}

Talahanayan 7. Antas ng paggamit ng uri ng Dulog sa Panitikan batay sa Pamamaraang Tanong-Sagot

\begin{tabular}{|l|l|l|l|l|}
\hline Mga Pahayag & Mean & SD & Puna \\
\hline $\begin{array}{l}\text { Lumulutang ang pagiging malikhain sa paglikha ng mga katanungan } \\
\text { gamit ang google classroom. }\end{array}$ & 4.55 & 0.52 & Ganap na Sumasang-ayon \\
\hline $\begin{array}{l}\text { Mas nabibigyang pansin ang kakayahang maglahad ng saloobin at } \\
\text { kaisipan ng mga mag-aaral. }\end{array}$ & 4.55 & 0.52 & Ganap na Sumasang-ayon \\
\hline $\begin{array}{l}\text { Napupukaw ang interes mula sa mga katanungang nilikha mula sa } \\
\text { araling tinatalakay. }\end{array}$ & 4.64 & 0.50 & Ganap na Sumasang-ayon \\
\hline $\begin{array}{l}\text { Nahuhubog ang paraan ng pakikipagkomunikasyon ng guro at mag- } \\
\text { aaral sa oras ng talakayan. }\end{array}$ & 4.55 & 0.52 & Ganap na Sumasang-ayon \\
\hline $\begin{array}{l}\text { Nagiging aktibo sa oras ng talakayan ang mga mag-aaral batay sa } \\
\text { nilikhang mga katanungan ng guro. }\end{array}$ & 4.45 & 0.52 & Ganap na Sumasang-ayon \\
\hline $\begin{array}{l}\text { Sa pamamaraang ito napalilinang pa ng guro ang kakayahan na } \\
\text { bumuo ng makabuluhang katanungan ang mga mag-aaral batay sa } \\
\text { aralin. }\end{array}$ & 4.73 & 0.47 & Ganap na Sumasang-ayon \\
\hline Nasusuri ang mga kasagutang inilahad ng mga mag-aaral. & 4.73 & 0.47 & Ganap na Sumasang-ayon \\
\hline $\begin{array}{l}\text { Nabibigyang pansin ang paggamit ng wastong mga salita at bantas sa } \\
\text { likhang kasagutan ng mga mag-aaral }\end{array}$ & 4.27 & 0.79 & Ganap na Sumasang-ayon \\
\hline $\begin{array}{l}\text { Nahihikayat ang mga mag-aaral na maging bukas ang isipan sa } \\
\text { paglalahad ng kanilang saloobin at sa pagkuha ng opinion ng mga } \\
\text { kamag-aral }\end{array}$ & 4.64 & 0.50 & Ganap na Sumasang-ayon \\
\hline $\begin{array}{l}\text { Nasusubay-bayan ang paglago ng mga mag-aaral batay sa mga } \\
\text { mungkahing ibinibigay sa mga naging kamalian sa kanilang likhang } \\
\text { tanong at sagot. }\end{array}$ & 4.64 & 0.50 & Ganap na Sumasang-ayon \\
\hline
\end{tabular}




\section{EPRA International Journal of Research and Development (IJRD)}

\section{Overall Mean: 4.57}

Standard Deviation: 0.533

Literal na paliwanag: Lubhang Mataas

Talahanayan 8. Antas ng paggamit ng uri ng Dulog sa Panitikan batay sa Pamamaraang Paulat

\begin{tabular}{|l|l|l|l|}
\hline Mga Pahayag & Mean & SD & Puna \\
\hline $\begin{array}{l}\text { Nasusuri ang kakayahan ng mga mag-aaral sa paglalahad } \\
\text { ng kanilang saloobin, damdamin at kaisipan. }\end{array}$ & 4.64 & 0.50 & Ganap na Sumasang-ayon \\
\hline $\begin{array}{l}\text { Naiisa-isa ang kakayahan ng mga mag-aaral sa paraang ito } \\
\text { upang madevelop ang kumpiyansa sa sarili na humarap at } \\
\text { magsalita sa harap ng kaniyang kamag-aral. }\end{array}$ & 4.45 & 0.52 & Ganap na Sumasang-ayon \\
\hline $\begin{array}{l}\text { Ginagamit na pamamaraan upang maalis ang hiya ng mga } \\
\text { mag-aaral sa pagharap at pagsasalita lalo't maraming } \\
\text { tagapakinig/nakikinig }\end{array}$ & 4.55 & 0.52 & Ganap na Sumasang-ayon \\
\hline $\begin{array}{l}\text { Nabibigyang pansin ng guro ang pagiging malikhain ng } \\
\text { mga mag-aaral sa paraan ng pag-uulat batay sa } \\
\text { presentasyong ginawa. }\end{array}$ & 4.55 & 0.52 & Ganap na Sumasang-ayon \\
\hline $\begin{array}{l}\text { Napapalawak ng guro ang kaalaman ng mga mag-aaral } \\
\text { batay sa mga impormasyong nalikom ng mga mag-aaral at } \\
\text { nabibigyang linaw ang mga katanungan sa kanilang } \\
\text { isipan. }\end{array}$ & 4.64 & 0.50 & Ganap na Sumasang-ayon \\
\hline $\begin{array}{l}\text { Nahihikayat ng guro na mabibigyan ng pagkakataon ang } \\
\text { lahat ng mag-aaral na makapaglahad ng kanilang gawain. }\end{array}$ & 4.64 & 0.50 & Ganap na Sumasang-ayon \\
\hline $\begin{array}{l}\text { Naiisa-isa ng guro ang mga mag-aaral na kinakailangan } \\
\text { pang linangin ang paraan ng kanilang paglalahad. }\end{array}$ & 4.64 & 0.50 & Ganap na Sumasang-ayon \\
\hline $\begin{array}{l}\text { Nailelebel ng guro ang performans ng mga mag-aaral } \\
\text { mula sa kanilang mga naunang pag-uulat at sa pag-uulat } \\
\text { pang ginagawa. }\end{array}$ & 4.45 & 0.52 & Ganap na Sumasang-ayon \\
\hline $\begin{array}{l}\text { Napatataas ng guro ang lebel ng paglalahad ng mga } \\
\text { kaisipan ng mga mag-aaral sa tiyak na aralin. }\end{array}$ & 4.64 & 0.50 & Ganap na Sumasang-ayon \\
\hline $\begin{array}{l}\text { Napalulutang ang kasiglahan ng mga mag-aaral mula sa } \\
\text { talakayang inihanda ng guro. }\end{array}$ & 4.55 & 0.52 & Ganap na Sumasang-ayon \\
\hline $\begin{array}{l}\text { Overall Mean: 4.57 } \\
\text { Standard Deviation: 0.497 } \\
\text { Literal na paliwanag: Lubhang Mataas }\end{array}$ & & & \\
\hline
\end{tabular}

Talahanayan 9. Antas ng paggamit ng uri ng Dulog sa Panitikan batay sa Pagkakatutong Interaktibo

\begin{tabular}{|l|l|l|l|}
\hline Mga Pahayag & Mean & SD & Puna \\
\hline $\begin{array}{l}\text { Nalilinang ng guro ang kakayahang makikipag } \\
\text { komunikasyon ng mga mag-aaral sa paraan ng pagkuha } \\
\text { ng mungkahi sa kanyang kamag-aral }\end{array}$ & 4.64 & 0.50 & Ganap na Sumasang-ayon \\
\hline $\begin{array}{l}\text { Nagkakaroon ng magandang kolaborasyon sa pagitan ng } \\
\text { guro at grupo ng mga mag-aaral sa paggawa ng kanilang } \\
\text { aktibidad. }\end{array}$ & 4.73 & 0.47 & Ganap na Sumasang-ayon \\
\hline $\begin{array}{l}\text { Nasusuri ng guro ang kakayahan ng mga mag-aaral sa } \\
\text { pagbibigay ng kani-kanilang pagka-unawa sa nilalaman } \\
\text { ng isang aralin. }\end{array}$ & 4.73 & 0.47 & Ganap na Sumasang-ayon \\
\hline $\begin{array}{l}\text { Nalilinang ng guro ang abilidad ng mga mag-aaral na } \\
\text { maging isang lider. }\end{array}$ & 4.55 & 0.52 & Ganap na Sumasang-ayon \\
\hline $\begin{array}{l}\text { Nagagabayan ng guro ang paraan ng paglalahad ng mga } \\
\text { mag-aaral at nakapipili ng mga wastong salitang } \\
\text { gagamitin para sa pag-uulat. }\end{array}$ & 4.64 & 0.50 & \\
\hline
\end{tabular}




\section{EPRA International Journal of Research and Development (IJRD)}

- Peer Reviewed Journal

\begin{tabular}{|l|l|l|c|}
\hline $\begin{array}{l}\text { Nabubuhay ng guro ang pagkakaisa ng bawat pangkat sa } \\
\text { paglikha ng gawain. }\end{array}$ & 4.64 & 0.50 & Ganap na Sumasang-ayon \\
\hline $\begin{array}{l}\text { Naiisa-isa ng guro ang talento ng mga mag-aaral batay sa } \\
\text { mga gawaing naiatang sa kanilang pangkat. }\end{array}$ & 4.55 & 0.52 & Ganap na Sumasang-ayon \\
\hline $\begin{array}{l}\text { Natutukoy ng guro ang mga mag-aaral na aktibo sa mga } \\
\text { gawaing ibinahagi sa kanilang grupo. }\end{array}$ & 4.73 & 0.47 & Ganap na Sumasang-ayon \\
\hline $\begin{array}{l}\text { Nagiging alisto at handa ang mga mag-aaral batay sa } \\
\text { nilikhang gawain ng guro. }\end{array}$ & 4.64 & 0.50 & Ganap na Sumasang-ayon \\
\hline $\begin{array}{l}\text { Malayang nakapagbibigay ng saloobin at kaalaman ang } \\
\text { mga mag-aaral tungkol sa inilatag na aktibidad ng guro. }\end{array}$ & 4.64 & 0.50 & \\
\hline $\begin{array}{l}\text { Overall Mean: 4.65 } \\
\text { Standard Deviation: 0.481 } \\
\text { Literal na paliwanag: Lubhang Mataas }\end{array}$ & & \\
\hline
\end{tabular}

Talahanayan 10. Antas ng paggamit ng Uri ng Dulog sa Wika batay sa Pamamaraang Pabuod

\begin{tabular}{|l|l|l|l|}
\hline Mga Pahayag & Mean & \multicolumn{1}{|c|}{ SD } & Puna \\
\hline $\begin{array}{l}\text { Nabibigyang pansin ng guro ang paraan ng pagkaunawa } \\
\text { ng mga mag-aaral sa akda. }\end{array}$ & 4.73 & 0.47 & Ganap na Sumasang-ayon \\
\hline $\begin{array}{l}\text { Nabibigyang diin ng guro ang paraan ng pagbubuod ng } \\
\text { mag-aaral ayon sa kanilang pagkatuto. }\end{array}$ & 4.64 & 0.50 & Ganap na Sumasang-ayon \\
\hline $\begin{array}{l}\text { Nakagagamit ng wastong pamamaraan ng pagbubuod } \\
\text { ang mga mag-aaral batay sa tinalakay na pamamaraan ng } \\
\text { guro. }\end{array}$ & 4.73 & 0.47 & Ganap na Sumasang-ayon \\
\hline $\begin{array}{l}\text { Nasusukat ng guro ang kakayahan ng mga mag-aaral sa } \\
\text { pagpili ng mahahalagang kaganapan sa kwento. }\end{array}$ & 4.64 & 0.50 & Ganap na Sumasang-ayon \\
\hline $\begin{array}{l}\text { Nalilinang ng guro ang kritikal na pag-iisip at } \\
\text { pagkaunawa ng mga mag-aaral mula sa nilalaman ng } \\
\text { akdang binasa at tinalakay. }\end{array}$ & 4.45 & 0.52 & Ganap na Sumasang-ayon \\
\hline $\begin{array}{l}\text { Napaiisa-isa ng guro ang mahahalagang sangkap sa } \\
\text { pagbubuod ng isang akda sa mga mag-aaral at ito ang } \\
\text { nagiging gabay ng mga mag-aaral. }\end{array}$ & 4.64 & 0.50 & Ganap na Sumasang-ayon \\
\hline $\begin{array}{l}\text { Natutukoy ng guro ang pang-unawa ng mag-aaral mula } \\
\text { sa buod ng kanilang nilikha. }\end{array}$ & 4.64 & 0.50 & Ganap na Sumasang-ayon \\
\hline $\begin{array}{l}\text { Nakagagamit ng iba't ibang pamamaraan ang guro upang } \\
\text { mabilis na mailahad ang pangyayari patungo sa mga } \\
\text { mag-aaral. }\end{array}$ & 4.64 & 0.50 & Ganap na Sumasang-ayon \\
\hline $\begin{array}{l}\text { Napalulutang ng guro ang pagiging malikhain ng mag- } \\
\text { aaral sa pag-uumisa ng pagbabalangkas at pagtatapos ng } \\
\text { paglalahad sa pagbubuod ng kwento. }\end{array}$ & 4.55 & 0.52 & Ganap na Sumasang-ayon \\
\hline $\begin{array}{l}\text { Nabibigyang pansin ng guro ang mga mag-aaral na } \\
\text { kinakailangan pa ng gabay sa gawaig ito. }\end{array}$ & 4.55 & 0.52 & Ganap na Sumasang-ayon \\
\hline $\begin{array}{l}\text { Overall Mean: 4.62 } \\
\text { Standard Deviation: 0.488 } \\
\text { Literal na paliwanag: Lubhang Mataas }\end{array}$ & & \\
\hline
\end{tabular}




\section{EPRA International Journal of Research and Development (IJRD)}

Talahanayan 11. Antas ng paggamit ng Uri ng Dulog sa Wika batay sa Pamamaraang Panayam

\begin{tabular}{|l|l|l|l|}
\hline Mga Pahayag & Mean & \multicolumn{1}{|c|}{ SD } & Puna \\
\hline $\begin{array}{l}\text { Nasusuri ang makabuluhang tanong tungkol sa aralin na } \\
\text { makapagbibigay ng malalim na persepsyon ang mga mag- } \\
\text { aaral. }\end{array}$ & 4.64 & 0.50 & Ganap na Sumasang-ayon \\
\hline $\begin{array}{l}\text { Napipili at naisasalansan ang mga salitang ginamit sa } \\
\text { pagbuo ng mga tanong. }\end{array}$ & 4.55 & 0.52 & Ganap na Sumasang-ayon \\
\hline $\begin{array}{l}\text { Nalilinang ng guro ang kritikal na pag-iisip ng mga mag- } \\
\text { aaral sa pagbuo at pagsagot sa mga nalikhang katanungan } \\
\text { mula sa aralin. }\end{array}$ & 4.45 & 0.52 & Ganap na Sumasang-ayon \\
\hline $\begin{array}{l}\text { Napalulutang ang pagiging malikhain sa paraan ng } \\
\text { pagkuha ng panayam at sa istilong gagamitin sa } \\
\text { pagsasagawa ng aktibidad. }\end{array}$ & 4.64 & 0.50 & Ganap na Sumasang-ayon \\
\hline $\begin{array}{l}\text { Nabibigyan ng oportunidad ng guro ang mga mag-aaral na } \\
\text { matuklasan nila ang kakayahan sa pakikipag-usap at sa } \\
\text { pagkuha ng panayam bilang isang propesyonal na } \\
\text { mananayam. }\end{array}$ & 0.64 & 0.50 & Ganap na Sumasang-ayon \\
\hline $\begin{array}{l}\text { Nakikita ng guro ang kakayahan na makapag-isip nang } \\
\text { mabilis ang mga mag-aaral. }\end{array}$ & 4.55 & 0.52 & Ganap na Sumasang-ayon \\
\hline $\begin{array}{l}\text { Naibabahagi ng guro ang paglalapat ng mga epektong } \\
\text { pantunog sa mga mag-aaral upang maging buhay ang } \\
\text { pakikipanayam. }\end{array}$ & 4.55 & 0.52 & Ganap na Sumasang-ayon \\
\hline $\begin{array}{l}\text { Nasusuri ng guro ang paraan ng pakikipanayam na ginawa } \\
\text { ng mga mag-aaral na ayon sa kraytirya ng gawain. }\end{array}$ & 4.64 & 0.50 & Ganap na Sumasang-ayon \\
\hline $\begin{array}{l}\text { Lumututang ang pagiging malikhain sa paggawa ng mga } \\
\text { kagamitang makikita sa pagkuha ng panayam. }\end{array}$ & 4.55 & 0.52 & Ganap na Sumasang-ayon \\
\hline $\begin{array}{l}\text { Nasusunod ang mga pamantayang inihanda ng guro batay } \\
\text { sa pagsusuri ng mga mag-aaral. }\end{array}$ & 4.64 & 0.50 & Ganap na Sumasang-ayon \\
\hline $\begin{array}{l}\text { Overall Mean: 4.58 } \\
\text { Standard Deviation: 0.496 } \\
\text { Literal na paliwanag: Lubhang Mataas }\end{array}$ & & \\
\hline
\end{tabular}

Talahanayan12. Makabuluhang epekto ang Profayl ng mga guro sa paggamit ng Uri ng Dulog sa Panitikan

\begin{tabular}{lcccc}
\hline Edad & Beta & t-value & p-value & Analysis \\
\hline Pamamaraang Tanong-Sagot & 0.035 & 17.901 & 0.000 & Significant \\
Pamamaraang Paulat & 0.085 & 17.328 & 0.000 & Significant \\
$\quad$ Pagkatutong Interaktibo & 0.045 & 18.35 & 0.000 & Significant \\
\hline Kasarian & & & \\
\hline Pamamaraang Tanong-Sagot & -0.013 & 9.957 & 0.000 & Significant \\
$\quad$ Pamamaraang Paulat & 0.060 & 9.362 & 0.000 & Significant \\
$\quad$ Pagkatutong Interaktibo & 0.120 & 9.969 & 0.000 & Significant \\
\hline Kolehiyong Kinabibilangan & & & & \\
\hline Pamamaraang Tanong-Sagot & -0.146 & 11.240 & 0.000 & Significant \\
$\quad$ Pamamaraang Paulat & -0.329 & 11.884 & 0.000 & Significant \\
$\quad$ Pagkatutong Interaktibo & -0.154 & 11.557 & 0.000 & Significant \\
\hline Taon ng Pagtuturo & & & & \\
\hline Pamamaraang Tanong-Sagot & 0.111 & 16.609 & 0.000 & Significant
\end{tabular}




\section{EPRA International Journal of Research and Development (IJRD)}

Volume: 6 | Issue: 7 | July 2021

- Peer Reviewed Journal

Pamamaraang Paulat

0.098

15.163

0.000

Significant

Pagkatutong Interaktibo

0.116

17.443

0.000

Significant

Adjusted R-Square: 0.6393

F-value: $\quad 6.2208$

Sig.:

0.0342

Talahanayan 13. Makabuluhang epekto ang Profayl ng mga guro sa paggamit ng Uri ng Dulog sa Wika

\begin{tabular}{|c|c|c|c|c|}
\hline Edad & Beta & t-value & p-value & Analysis \\
\hline Pamamaraang Pabuod & 0.060 & 17.761 & 0.000 & Significant \\
\hline Pamamaraang Panayam & 0.070 & 16.817 & 0.000 & Significant \\
\hline \multicolumn{5}{|l|}{ Kasarian } \\
\hline Pamamaraang Pabuod & -0.040 & 9.9687 & 0.000 & Significant \\
\hline Pamamaraang Panayam & 0.003 & 9.297 & 0.000 & Significant \\
\hline \multicolumn{5}{|l|}{ Kolehiyong Kinabibilangan } \\
\hline Pamamaraang Pabuod & -0.392 & 12.815 & 0.000 & Significant \\
\hline Pamamaraang Panayam & -0.342 & 11.653 & 0.000 & Significant \\
\hline \multicolumn{5}{|l|}{ Taon ng Pagtuturo } \\
\hline Pamamaraang Pabuod & 0.106 & 16.069 & 0.000 & Significant \\
\hline Pamamaraang Panayam & 0.116 & 15.377 & 0.000 & Significant \\
\hline
\end{tabular}

Adjusted R-Square: 0.5853

F-value: $\quad 4.6901$

Sig.: $\quad 0.0485$

Talahanayan 14. Makabuluhang epekto ng kahandaan ng mga guro na nagtuturo ng asignaturang Filipino sa Paggamit ng google classroom batay sa Paggamit ng Dulog sa Panitikan

\begin{tabular}{llllc}
\hline Personal na Kamalayan & Beta & t-value & p-value & Analysis \\
\hline Pamamaraang Tanong-Sagot & 0.625 & 2.239 & 0.052 & Not Significant \\
Pamamaraang Paulat & 0.625 & 2.110 & 0.054 & Not Significant \\
Pagkatutong Interaktibo & 0.126 & 2.867 & 0.019 & Significant \\
\hline Kawilihan & & & Significant \\
\hline Pamamaraang Tanong-Sagot & -0.144 & 5.334 & 0.001 & Significant \\
Pamamaraang Paulat & 0.750 & 2.406 & 0.003 & Significant \\
Pagkatutong Interaktibo & 0.315 & 4.103 & 0.003 & \\
\hline Aksesibiliti & & & & Significant \\
\hline Pamamaraang Tanong-Sagot & 0.447 & 2.541 & 0.032 & Not Significant \\
Pamamaraang Paulat & 0.384 & 1.897 & 0.090 & Not Significant \\
Pagkatutong Interaktibo & 0.397 & 2.129 & 0.062 & Significant
\end{tabular}




\section{EPRA International Journal of Research and Development (IJRD)}

Volume: 6 | Issue: 7 | July 2021

- Peer Reviewed Journal

Pamamaraang Paulat

0.701

3.204

0.108

Not Significant

\begin{tabular}{l} 
Pagkatutong Interaktibo \\
\hline Talakayan \\
\hline Pamamaraang Tanong-Sago \\
Pamamaraang Paulat \\
Pagkatutong Interaktibo \\
\hline Takdang Aralin \\
\hline Pamamaraang Tanong-Sago \\
Pamamaraang Paulat \\
Pagkatutong Interaktibo \\
Adjusted R-Square: 0.8330 \\
F-value: \\
Sig.: \\
$\begin{array}{l}\text { Pal } \\
\text { Pand }\end{array}$
\end{tabular}

Talahanayan 15. Makabuluhang epekto ng kahandaan ng mga guro na nagtuturo ng asignaturang Filipino sa Paggamit ng google classroom batay sa Paggamit ng Dulog sa Wika

\begin{tabular}{|c|c|c|c|c|}
\hline Personal na Kamalayan & Beta & t-value & $\mathrm{p}$-value & Analysis \\
\hline Pamamaraang Pabuod & 0.758 & 2.104 & 0.065 & Not Significant \\
\hline Pamamaraang Panayam & 0.369 & 2.239 & 0.052 & Not Significant \\
\hline \multicolumn{5}{|l|}{ Kawilihan } \\
\hline Pamamaraang Pabuod & 0.699 & 2.223 & 0.053 & Not Significant \\
\hline Pamamaraang Panayam & 0.744 & 2.668 & 0.026 & Significant \\
\hline \multicolumn{5}{|l|}{ Aksesibiliti } \\
\hline Pamamaraang Pabuod & 0.455 & 2.539 & 0.032 & Significant \\
\hline Pamamaraang Panayam & 0.424 & 2.103 & 0.065 & Not Significant \\
\hline \multicolumn{5}{|l|}{ Pagsasanay } \\
\hline Pamamaraang Pabuod & 0.803 & 4.922 & 0.001 & Significant \\
\hline Pamamaraang Panayam & 0.745 & 3.469 & 0.007 & Significant \\
\hline \multicolumn{5}{|l|}{ Talakayan } \\
\hline Pamamaraang Pabuod & 0.788 & 4.266 & 0.002 & Significant \\
\hline Pamamaraang Panayam & 0.824 & 4.369 & 0.002 & Significant \\
\hline \multicolumn{5}{|l|}{ Takdang Aralin } \\
\hline Pamamaraang Pabuod & 0.540 & 3.166 & 0.011 & Significant \\
\hline Pamamaraang Panayam & 0.768 & 2.553 & 0.031 & Significant \\
\hline
\end{tabular}

Adjusted R-Square: 0.8229

F-value: $\quad 18.883$

Sig.: $\quad 0.0019$ 


\section{EPRA International Journal of Research and Development (IJRD)}

Volume: 6 | Issue: 7 | July 2021

- Peer Reviewed Journal

\section{TALASANGGUNIAN}

\section{INTERNET}

1. Etikan, Musa, \& Alkassim 2016, https://www.wattpad.com/Pananaliksik sa Gramatikang Filipino

2. Santiago, A. (2011) GENYO e-learning. What are you all about? Retrieved from http://itswyza.wordpress.com/2011 